\title{
Strategies for implementing placental transfusion at birth
}

\section{Authors:}

Oana Anton ${ }^{1,2}$, Harriet Jordan ${ }^{1}$, Christina Jones ${ }^{3}$, Heike Rabe ${ }^{1,2,3}$

1. Academic Department of Pediatrics, Brighton and Sussex University Hospitals, Royal Alexandra Hospital for Children, Brighton, UK

2. Trevor Mann Baby Unit, Brighton and Sussex University Hospitals, Brighton

3. Academic Department of Pediatrics, Brighton and Sussex Medical School, Brighton, UK

\section{Background:}

Enhanced placental transfusion reduces adverse neonatal outcomes, including death. Despite being endorsed by the World Health Organization in 2014, PT at birth has not been adopted in practice. The aims of our review were to explore methods of implementation, identify barriers and strategies to facilitate PT at birth. (see table 1 for stakeholders endorsements)

\begin{tabular}{|c|l|l|}
\hline \multicolumn{3}{|c|}{ Table 1: A summary of endorsements from stakeholders } \\
\hline Organization & Preterm <37 weeks & Term $=>37$ weeks \\
\hline $\begin{array}{c}\text { WHO 2012, } \\
\text { 2014 }\end{array}$ & $\begin{array}{l}\text { Delay of umbilical cord clamping for 1-3 minutes is recommended for all births with simultaneous } \\
\text { essential newborn care }\end{array}$ \\
\hline ILCOR 2015 & $\begin{array}{l}\text { Delay umbilical cord clamping for at least 1 minute in both term and preterm infants who do not } \\
\text { require resuscitation at birth. Evidence does not support or refute delayed cord clamping when } \\
\text { resuscitation is needed }\end{array}$ \\
\hline RCOG 2016 & $\begin{array}{l}\text { Routine early clamping of the umbilical cord no longer } \\
\text { recommended. Umbilical cord should not be clamped } \\
\text { earlier than 1 minute if there are no concerns over cord } \\
\text { integrity or the baby's well-being }\end{array}$ & $\begin{array}{l}\text { In healthy term babies, practice } \\
\text { "deferred" cord clamping (delay } \\
\text { clamping for at least 2 minutes) }\end{array}$ \\
\hline SOGC 2016 & $\begin{array}{l}\text { Delayed cord clamping by at least 60 seconds is } \\
\text { recommended irrespective of mode of delivery }\end{array}$ & $\begin{array}{l}\text { The risk of jaundice is weighed } \\
\text { against the physiological } \\
\text { benefits of delayed cord } \\
\text { clamping }\end{array}$ \\
\hline AAP 2017 & Endorse recommendations of ACOG 2017 \\
\hline ACOG 2017 & At least 30 - 60 second delay in cord clamping in vigorous term and preterm infant \\
\hline $\begin{array}{l}\text { Abbreviations: AAP- American Academy of Pediatrics, ACOG- American College of Obstetricians and } \\
\text { Gynecologists, ILCOR- International Liaison Committee on Resuscitation, RCOG- Royal College of Obstetricians } \\
\text { and Gynecologists, SOGC- Society of Obstetricians and Gynecologists of Canada, WHO- World Health } \\
\text { Organization }\end{array}$ \\
\hline
\end{tabular}

\section{Methods:}

Systematic literature search on E-pub Ahead of Print, In-Process \& Other Non-Indexed Citations (OVID), MEDLINE (OVID). MEDLINE Daily (OVID) and The Cochrane Library (Wiley).

\section{- Inclusion criteria:}

Quality improvement projects on placental transfusion at birth and studies on barriers to implementation

Published in the last ten years, no language restrictions

See fig 1 a flowchart with identification and selection of studies

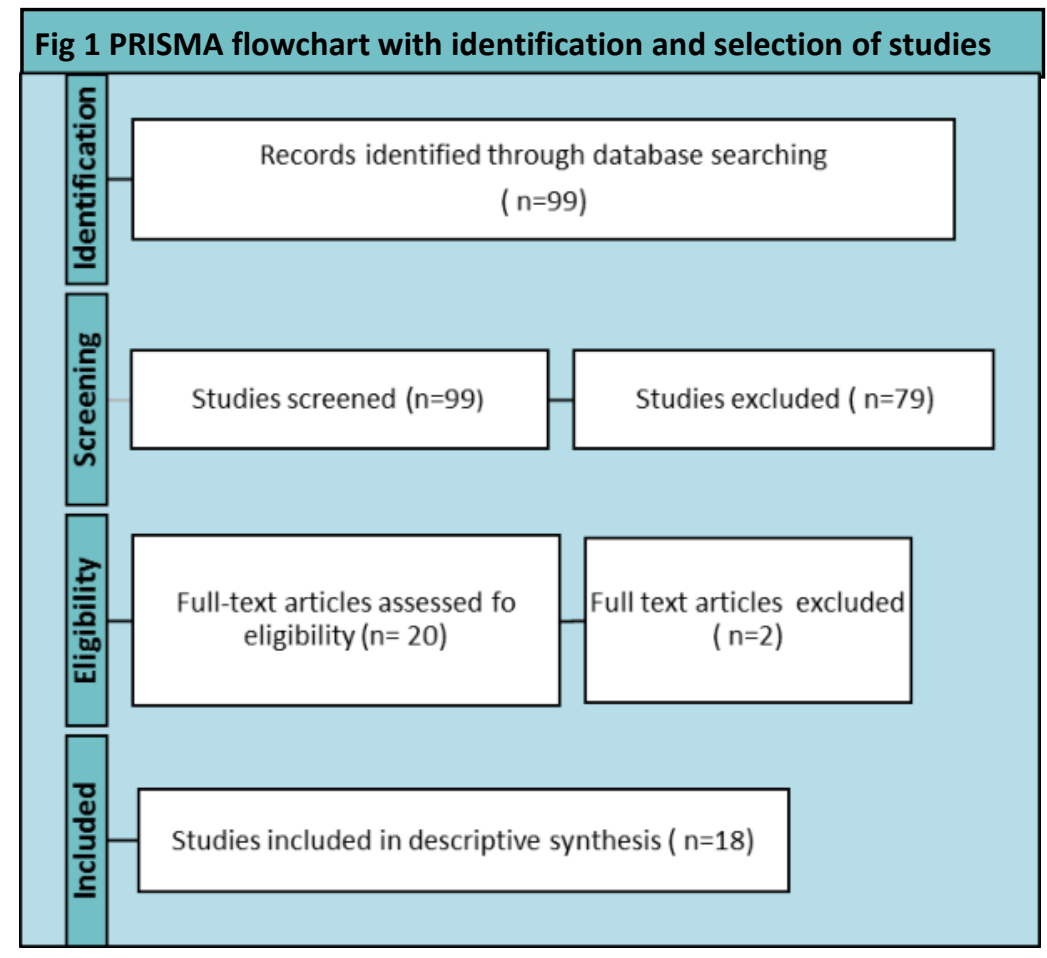

- Data extracted in Excel table producing a summary of review studies

$\checkmark$ General information: country, publication year, study setting, study type, study aims, population (gestation age, sample size)

$\checkmark$ Intervention: methods of placental transfusion, type of professional involved

$\checkmark$ Methods of evaluating intervention, obstacles and strategies to overcome obstacles

- Analysis: Excel table with summary of studies was analysed using descriptive statistics
Results

The studies included in this review had different designs ( see table 2)

\begin{tabular}{|l|l|l|l|l|l|}
\hline \multicolumn{5}{|l|}{ Table 2 Summary of studies' methodology } \\
\hline Data available & \multicolumn{4}{|l|}{ Only on barriers to placental transfusion } & \multicolumn{3}{l|}{ Implementation methods and barriers } \\
\hline Study design & $\begin{array}{l}\text { Qualitative study } \\
\text { questionnaires }\end{array}$ & $\begin{array}{l}\text { Quality } \\
\text { improvement } \\
\text { study }\end{array}$ & $\begin{array}{l}\text { Quality } \\
\text { improvement } \\
\text { study }\end{array}$ & $\begin{array}{l}\text { Retrospective } \\
\text { cohort study }\end{array}$ & $\begin{array}{l}\text { Audit of } \\
\text { practice }\end{array}$ \\
\hline Number of studies & 2 & 1 & 10 & 3 & 1 \\
\hline
\end{tabular}

The preferred methods of implementation were protocol development, targeted education, multidisciplinary team involvement and audit of clinical practice (see Table 3).

The top barriers to implementations were: neonatal concerns (need for resuscitation, risk of jaundice and polycythaemia), logistical difficulties (no guidance for resuscitation with the cord intact, ensuring normothermia and sterility of the environment) and obstetric concerns (risk of postpartum haemorrhage) (see table 4 for details).

Main strategies to facilitate placental transfusion at birth included: targeted education (58\% of studies), protocol development (50\% of studies) and constructive feedback sessions $33 \%$ of studies).

\begin{tabular}{|l|l|}
\hline Table 3 Preferred methods of implementation \\
\hline Method of Implementation & $\begin{array}{l}\text { Number of } \\
\text { studies }\end{array}$ \\
\hline Protocol & $12(86 \%)$ \\
\hline Education & $9(64 \%)$ \\
\hline Multi-disciplinary team approach & $6(43 \%)$ \\
\hline Audit/data collection on PT practice & $4(29 \%)$ \\
\hline Simulation training & $2(14 \%)$ \\
\hline Visual aids & $3(21 \%)$ \\
\hline Addressing concerns & $3(21 \%)$ \\
\hline Champions & $2(14 \%)$ \\
\hline Targeted feedback & $1(7 \%)$ \\
\hline
\end{tabular}

\section{Discussion}

High level of overlap between strategies to implement, evaluate, improve compliance and overcome barriers

High level of bias due to heterogeneity of studies

Quality improvement projects are the most popular to implement placental transfusion

We propose a stepwise approach to setting up implementation using a "Plan Do Study Act" (PDSA ) see figure 2

\begin{tabular}{|l|l|}
\hline \multicolumn{2}{|l|}{ Table 4 Barriers to implementation } \\
\hline Barrier & $\begin{array}{l}\text { Number of } \\
\text { studies }\end{array}$ \\
\hline GENERAL FACTORS & $5(41 \%)$ \\
\hline Knowledge of staff & 5 . \\
\hline $\begin{array}{l}\text { Professional resistance to change } \\
\text { (obstetrician automated process } \\
\text { of delivery, anxiety, fixed beliefs) }\end{array}$ & $5(41 \%)$ \\
\hline $\begin{array}{l}\text { Difficulty implementing } \\
\text { change/lack of quality } \\
\text { improvement experience }\end{array}$ & $4(33 \%)$ \\
\hline $\begin{array}{l}\text { Lack of guideline/exclusion } \\
\text { criteria/delayed cord clamping } \\
\text { definition }\end{array}$ & $3(25 \%)$ \\
\hline OBSTETRICIAN CONCERNS & $3(25 \%)$ \\
\hline PPH & $3(25 \%)$ \\
\hline Caesarean section & $2(16.6 \%)$ \\
\hline Uterotonic drug use & $2(16.6 \%)$ \\
\hline Placental or cord disruption & $5(41 \%)$ \\
\hline PAEDIATRICIAN CONCERNS & $3(25 \%)$ \\
\hline $\begin{array}{l}\text { Neonatal safety/need for } \\
\text { resuscitation }\end{array}$ & $2(16.6 \%)$ \\
\hline Jaundice & $1(8.3 \%)$ \\
\hline Polycythemia & $3(25 \%)$ \\
\hline Preterm & $2(16.6 \%)$ \\
\hline ENVIRONMENTAL CHALLENGE \\
\hline $\begin{array}{l}\text { Logistics (equipment/practical } \\
\text { procedures) during delayed cord } \\
\text { clamping }\end{array}$ \\
\hline $\begin{array}{l}\text { Delivery room temperature + } \\
\text { neonatal hypothermia risk }\end{array}$ & 3 \\
\hline
\end{tabular}

\begin{tabular}{|c|c|c|c|c|c|c|c|}
\hline 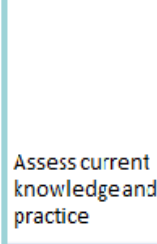 & & $\begin{array}{l}\text { Address concerns } \\
\text { and receive } \\
\text { feedbackfrom } \\
\text { stakeholdersat } \\
\text { MOT forums }\end{array}$ & & 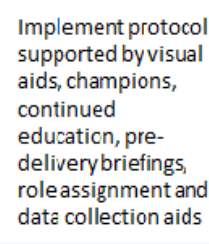 & & $\begin{array}{l}\text { Adjust protocol } \\
\text { acacordinglyand give } \\
\text { feedbact to } \\
\text { stakeholders }\end{array}$ & \\
\hline & $\begin{array}{l}\text { Develop a atargeted } \\
\text { eeduaction } \\
\text { programme }\end{array}$ & & $\begin{array}{l}\text { Create an evidence- } \\
\text { tased protocol with } \\
\text { deard definitions of } \\
\text { PT strategy, timinges, } \\
\text { exclusion criteria } \\
\text { and emergency } \\
\text { situations }\end{array}$ & & $\begin{array}{l}\text { Monitor rractic } \\
\text { and dollecti } \\
\text { feedback }\end{array}$ & & \\
\hline
\end{tabular}

\section{Conclusions}

$\checkmark$ A successful placental transfusion strategy requires a multi-step approach

$\checkmark$ The development of a protocol is vital to placental transfusion implementation, with clear definitions of timings, methods and exclusion criteria

$\checkmark$ Placental transfusion implementation requires a multidisciplinary approach, with Obstetricians, Midwives, Nurses and Pediatricians central to adoption of practice $\checkmark$ Interventions must also be continually reassessed and supported

$\checkmark$ To ultimately achieve a system change we stress the importance of continuous feedback to key stakeholders through debriefing, meetings and audit.

References:

1. Rabe H, Diaz-Rossello JL, Duley L, Dowswell T. Effect of timing of umbilical cord clamping and other strategies to influence placental transfusion at preterm birth on maternal and infant outcomes. Cochrane Database Systematic Rev. 2012(8):CD003248.

2. Backes $\mathrm{CH}$, Rivera BK, Haque U, Bridge JA, Smith CV, Hutchon DJ, et al. Placental transfusion strategies in very preterm neonates: a systematic review and meta-analysis. Obstetrics \& Gynecology. 2014;124(1):47-56.

3. Fogarty M, Osborn DA, Askie L, Seidler AL, Hunter K, Lui K, et al. Delayed vs early umbilical cord clamping for preterm infants: a systematic review and meta-analysis. American Journal of Obstetrics \& Gynecology. 2018;218(1):1-18.

4. WHO. Guideline: Delayed umbilical cord clamping for improved maternal and infant health and nutrition outcomes. Geneva, World Health Organization; 2014 (http://www.who.int/nutrition/publications/guidelines/cord_clamping/en/). 